\title{
Crystal structure and spectroscopic properties of 4-acetaminopyridine and its protonated form
}

\author{
Bojidarka B. Koleva ${ }^{1 *}$, Rositsa Nikolova ${ }^{2}$, Atanas Tchapkanov ${ }^{3}$, Tsonko Kolev ${ }^{5}$, Heike Mayer- \\ Figge $^{1}$, Michael Spiteller ${ }^{4}$, William S. Sheldrick ${ }^{1}$ \\ ${ }^{1}$ Lehrstuhl für Analytische Chemie, Ruhr-Universität Bochum, Universitätsstraße 150, 44780 Bochum, Germany. \\ ${ }^{2}$ University of Sofia "St. Kl. Ohridsky", Department of Organic Chemistry, Sofia 1164, Bulgaria \\ ${ }^{3}$ South-West University, Department of Chemistry, Blagoevgrad 1341, Bulgaria \\ ${ }^{4}$ Institut für Umweltforschung, Universität Dortmund, Otto-Hahn-Strasse 6, 44221 Dortmund, Germany \\ * Corresponding author: e-mail: BKoleva@chem.uni-sofia.bg
}

\begin{abstract}
4-Acetaminopyridine dihydrate and its protonated form, stabilized as the hydrochloride salt have been synthesized and spectroscopic elucidated in solution and in the solid-state by means of the inear-polarized solid state IR-spectroscopy (IR-LD), UV-spectroscopy, TGA, DSC, and the positive and negative ESI MS. Quantum chemical calculations were used to obtain the electronic structure, vibrational data and the electronic spectra. The spectroscopic and theoretical data are compared with the structure of the first compound obtained by single crystal X-ray diffraction. The effect of $\mathrm{N}_{\mathrm{py}}$ protonation on the optical and magnetic properties of a 4-acetaminopyridine is discussed.
\end{abstract}

Keywords: 4-Acetaminopyridine, protonated form, crystal structure, solid-state linear polarized IRspectroscopy, UV-spectroscopy, quantum chemical calculations, ${ }^{1} \mathrm{H}-$ and ${ }^{13} \mathrm{C}$ NMR, ESI MS, TGA and DSC.

\section{INTRODUCTION}

Aminopyridines are biologically active compounds. They act by an inhibition of the voltage-dependent $\mathrm{K}^{+}$channels ${ }^{1-3}$, due to their ability to facilitate nerve transmission. Aminopyridines have been applied to reverse anaesthesia and muscle relaxation ${ }^{4}$ and have been proposed as drugs for the treatment of multiple sclerosis ${ }^{5}$, myasthenia gravis ${ }^{6}$, spinal cord injuries ${ }^{7}$, botulism $^{8}$ and Alzheimer's disease' ${ }^{9}$. Aminopyridines are weak bases that can exist in either the neutral or the cationic protonated form at physiological $\mathrm{pH}$. This characteristic complicates the elucidation of the mechanism and the site of action ${ }^{\mathbf{1 0 , 1 1}}$. On the other hand, the amides of the aminopyridines have been intensively studied in the co-crystallization processes that are currently receiving considerable attention, partly because of fundamental interest in molecular-recognition driven assembly procedured. As part of our systematic study of pyridine derivatives and their protonated forms ${ }^{12-17}$, we now present a spectroscopic and structural study of 4-acetaminopyridine dihydrate (1) and its $\mathrm{N}_{\mathrm{py}}$ protonated form (2), both in the solution and in the solid state using the methods of single crystal X-ray diffraction, ${ }^{1} \mathrm{H}$ - and ${ }^{13} \mathrm{C}-\mathrm{NMR}$, positive and negative ESI mass spectrometry, UV-spectroscopy, conventional and linear polarized IR-spectroscopy, and the TGA and DSC analysis. Quantum chemical calculations at the DFT, MP2 and CIS levels of theory and the $6-311++\mathrm{G}^{* *}$ basis set are employed for predicting and supporting the experimentally observed optical properties.

Despite the fact that aminopyridinium derivatives have been widely investigated in the past only three crystal structures of 4-acetaminopyridine, bis(acetato-O)-bis(4(N-acetylamino)pyridine)-aqua-copper(II) ${ }^{18}$, bis(hydrogen fluoride) dihydrate bis(4-acetaminopyridine) decandioic acid $^{19}$ and 4 -acetaminopyridinium hydrogenglutarate ${ }^{19}$. We now reported the crystal structure of 4-acetaminopyridine dihydrate (1).

\section{EXPERIMENTAL}

\section{Methods}

The $X$-ray diffraction intensities were measured in the $\omega$ scan mode on a Siemens P4 diffractometer equipped with Mo $\mathrm{K}_{\alpha}$ radiation $\left(\lambda=0.71073 \AA \theta_{\max }=25^{\circ}\right)$ and the structure was solved by direct methods and refined against $\mathrm{F}^{2}$ 20,21. An ORTEP plot illustrates the anion and cation structures at the $50 \%$ probability level. Relevant crystallographic structure data and refinement details are presented in Table 1, the selected bond distances and angles in Table 2. The hydrogen atoms were constrained to calculated positions and refined using riding models in all the cases.

Conventional and polarized IR-spectra were measured on a Thermo Nicolet OMNIC FTIR-spectrometer (4000 $-400 \mathrm{~cm}^{-1}, 2 \mathrm{~cm}^{-1}$ resolution, 200 scans) equipped with a Specac wire-grid polarizer. The non-polarized solidstate IR spectra were recorded using the $\mathrm{KBr}$ disk technique. The oriented samples were obtained as a colloid suspension in a nematic liquid crystal ZLI 1695. The theoretical approach and the experimental technique for preparing the samples as well as the procedures for the polarized IR-spectra interpretation and the validation of this new linear-dichroic infrared (IR-LD) orientation solidstate method for accuracy and precision have been previously presented $\mathrm{d}^{22-25}$. The influence of the liquid crystal medium on the peak positions and the integral absorbances of the guest molecule bands, the reological model, the nature and balance of the forces in the nematic liquid crystal suspension system, and the morphology of the suspended particles have also been discussed ${ }^{22-25}$.

The positive and negative ESI mass spectra were recorded on a Fisons VG Autospec instrument employing 3-nitrobenzylalcohol (Sigma-Aldrich) as the matrix.

Ultraviolet (UV-) spectra were recorded on Tecan Safire Absorbance/Fluorescence XFluor 4 V 4.40 spectrophotometer operating between 190 and $900 \mathrm{~nm}$, using the 


\section{RESULTS AND DISCUSSION}

\section{Crystallographic data of 4-Acetaminopyridine dihydrate (1)}

The asymmetric unit of 4-aetaminopyridine dihydrate, is depicted in Fig. 1. The compound crystallizes in the centrosymmetric space group $\mathrm{P} 2 / \mathrm{n}$ and contains two independent. The molecules of 4-aetaminopyridine are connected by moderate intermolecular hydrogen bonds to the co-crystallized water molecules in the structure, $\left(\mathrm{NH} . . . \mathrm{OH}_{2}(2.901,2.883 \AA), \mathrm{HOH} . . . \mathrm{O}=\mathrm{C}(2.832,2.819\right.$ $\AA$ ) and $\mathrm{HOH}$...Npy $(2.830,2.855 \AA)$, thus forming infinite layers (Fig. 2) at the stacking distance of $3.504 \AA$. The amide fragments exhibit a trans-configuration and are effectively planar with dihedral angle values of $177.3(6)^{\circ}$ and $179.7(8)^{\circ}$, respectively.

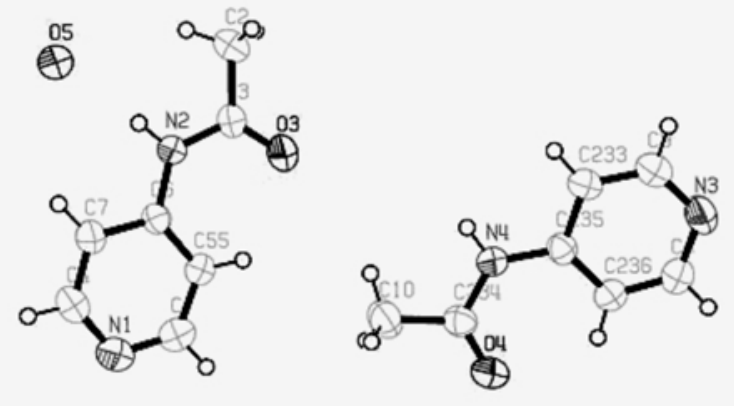

Q88

Figure 1. The structure of 4-acetaminopyridine dihydrate (1), showing the atom-labeling scheme in the independent molecules. Displacement ellipsoids are drawn at the $50 \%$ probability level

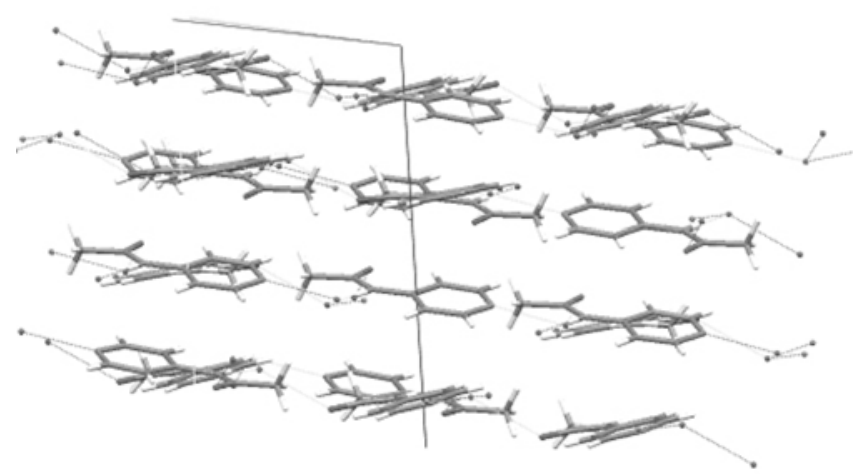

Figure 2. Hydrogen bonding in 4-acetaminopyridine dihydrate (1)

\section{Theoretical calculations}

The theoretical conformational analysis of the neutral and protonated form of 4-acetaminopyridine confirms the stabilization of trans-configuration of the amide fragment with $\mathrm{E}_{\text {rel }}$ values of $0.0 \mathrm{~kJ} / \mathrm{mol}$ (1) and $0.1 \mathrm{~kJ} / \mathrm{mol}$ (2) (Scheme 1), respectively. The dihedral $\mathrm{HN}-\mathrm{C}=\mathrm{O}$ angle of $179.9(9)^{\circ}$ in both cases correlates well with the X-ray structure for the neutral form. Bond lengths and angles are summarized in Scheme 1 and also indicate a good agreements between the theoretical approximation method and the experimental crystallographic data. Differences of less than $0.216 \AA$ and 2.4(1)o are observed (compare Table 2 and Scheme1).
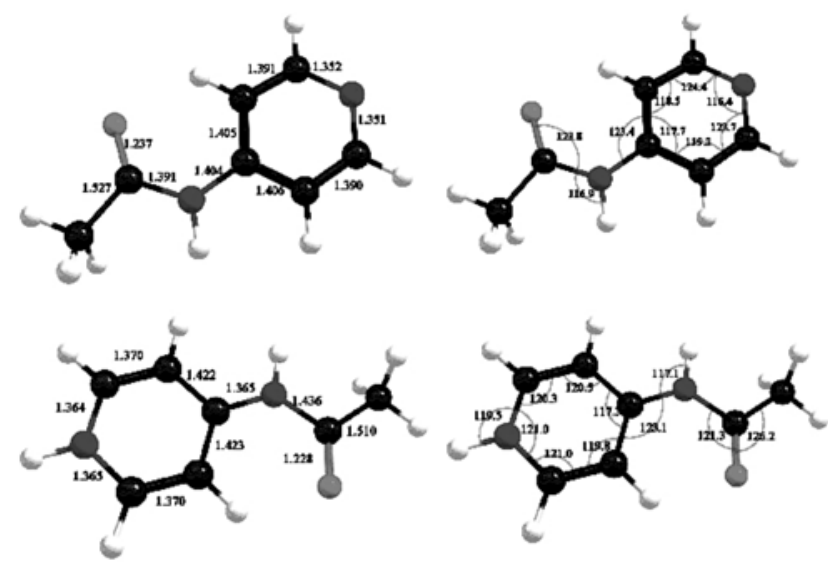

Scheme 1. Optimized geometry parameters

In contrast to the $\mathrm{N}_{\mathrm{py}}$ protonated forms of 4aminopyridine $^{\mathbf{1 4}}$ and 4-dimethylaminopyridine ${ }^{17}$, where the $\mathrm{N}_{\mathrm{py}}$ protonation leads to a distortion of the aromatic character of the pyridine ring and stabilization of the quinoid-like form, this process has no significant affect on the aromaticity of the skeleton of 4-acetaminopyridine. An illustration of this charge distribution of both forms (Scheme 2) shows that the $\mathrm{N}_{\mathrm{py}}$ protonation leads to a difference of $0.065 \mathrm{eV}$ the $\delta^{+}$charge of the $\mathrm{N}_{\mathrm{py}}$ nitrogen.

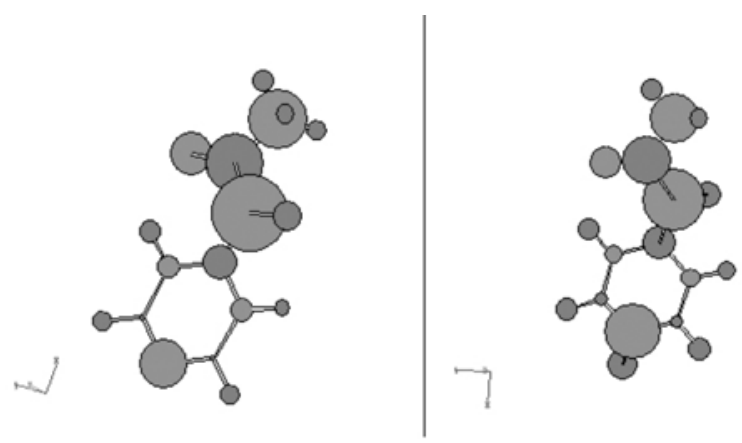

Scheme 2. Chemical diagram of the single charge electron density distribution

Additional confirmation of this finding follows from the theoretical IR-spectra (Fig.3), where the main differences between (1) and (2) are connected with the presence of the protonated $\mathrm{N}^{+} \mathrm{H}$ group in the second case leading to corresponding characteristic stretching and bending vibrations (Scheme 3 ). The $v_{\mathrm{N}+\mathrm{H}}$ vibration is obtained at a lower frequency than that of $\mathrm{nNH}\left(3488 \mathrm{~cm}^{-1}\right.$ and 3383 $\left.\mathrm{cm}^{-1}\right)$. In contrast, the bending $\delta_{\mathrm{N}+\mathrm{H}}$ band shifted to a higher frequency $\left(1571 \mathrm{~cm}^{-1}\right)$ than the corresponding band of dNH (Amide II, $1471 \mathrm{~cm}^{-1}$ ). The in-plane (i.p.) and out-of-plane (o.p.) modes of the pyridine fragments are practically unaffected by the $\mathrm{N}_{\mathrm{py}}$ protonation. The $\mathrm{v}_{\mathrm{C}=\mathrm{O}}$ (Amide I) band is obtained at about $1685 \mathrm{~cm}^{-1}$ in the neutral form and at about $1706 \mathrm{~cm}^{-1}$ in the corresponding protonated form. The $v_{\mathrm{NH}}$ stretching vibration in the neutral form is observed at $3398 \mathrm{~cm}^{-1}$ which represents a shift of $90 \mathrm{~cm}^{-1}$ to lower frequency in comparison to protonated form. We can conclude that the amidation of 4aminopyridine hinders the formation of the quinoid-like form, that is typical of the $\mathrm{N}_{\text {py }}$ protonated salts 4- 
aminopyridine and 4-dimethylaminopyridine ${ }^{\mathbf{1 4}, 17}$. Additional confirmation follows from the calculated low frequency shifting of the pyridine o.p. mode from $830 \mathrm{~cm}^{-1}$ in the neutral form to $762 \mathrm{~cm}^{-1}$ in the protonated one (Scheme 3), which can be described as a monosubstituted aromatic fragment.

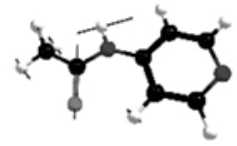

$1685 \mathrm{~cm}^{-1}$

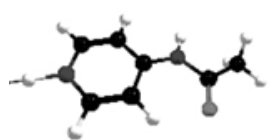

$1611 \mathrm{~cm}^{-1}$

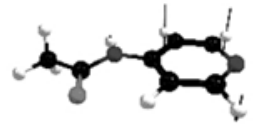

$830 \mathrm{~cm}^{-1}$

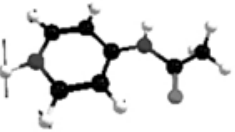

$1706 \mathrm{~cm}^{-1}$

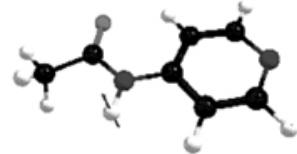

$596 \mathrm{~cm}^{-1}$

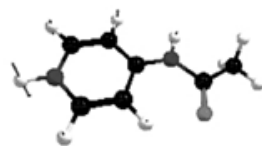

$762 \mathrm{~cm}^{-1}$
Scheme 3. Visualization of selected transition moments in (1) and (2)

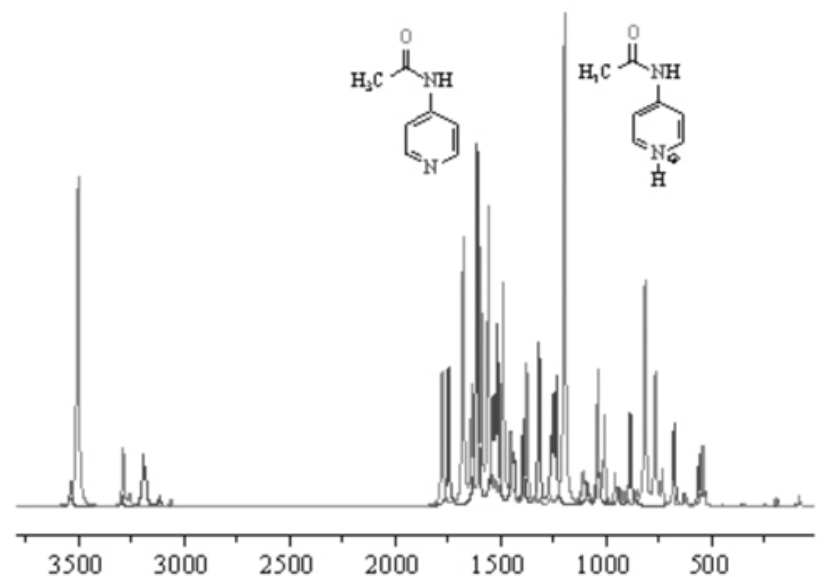

Figure 3. Theoretical IR spectra of the neutral and protonated forms of 4-acetaminopyridine
Conventional and linear-polarized IR-spectra

The theoretical conclusions were confirmed experimentally by investigating the conventional and linear polarized IR-spectra of (1) and (2) (Fig. 4). The $v_{\mathrm{NH}}$ stretching vibration is observed at $3440 \mathrm{~cm}^{-1}$ in (1), while the band is shifted at lower frequency to $3423 \mathrm{~cm}^{-1}$ in (2). The $v_{\mathrm{N}+\mathrm{H}}$ vibration is observed as a relatively broad band at 3469 $\mathrm{cm}^{-1}$ in the spectrum in Fig. 4.2. The amide I modes are observed as strond intensive bands at $1687 \mathrm{~cm}^{-1}$ (1) and $1675 \mathrm{~cm}^{-1}$ (2), respectively. The intensive band at $1712 \mathrm{~cm}^{-}$ ${ }^{1}$ in Fig. 4.2 can be assigned to $\delta_{\mathrm{N}+\mathrm{H}}$ and exhibits a typical value for a protonated $\mathrm{N}^{+} \mathrm{H}$ group in the pyridines ${ }^{12-17}$. The intensive o.p. bands of (1) and (2) are at $833 \mathrm{~cm}^{-1}$ and $763 \mathrm{~cm}^{-1}$, correlating well with the theoretically predicted values (see above). The $\gamma_{\mathrm{NH}}$ deformation vibrations are observed as broad bands at $636 \mathrm{~cm}^{-1}$ (1) and $598 \mathrm{~cm}^{-1}$ (2), respectively.

The elimination of the amide I band in both compounds leads to the disappearance of the IR-band of the corresponding $v_{\mathrm{NH}}$ stretching vibration (Fig.4.3), indicating the trans-configuration of the amide fragments, the state of affairs that was theoretically predicted for both compounds and experimentally confirmed by single crystal X-ray diffraction of (1). In the case of (1) the procedure leads to the observation of second pairs of maxima with the same origin, due to the presence of two independent molecules of 4-acetaminopyridine (Figs. 4.3 and 1) in the unit cell.

\section{UV-spectra}

The UV-spectra of the compounds (1) and (2) are depicted in Fig. 5. A comparison with the data of the salt of the monoprotonated 4-aminopyridine as well as that of 4dimethylaminopyridine and 3,4-dimethylaminopyridine salts ${ }^{14-16}$ show that compound (1) is characterized by two maxima at $240 \mathrm{~nm}\left(\pi \rightarrow \pi^{*}, \varepsilon 123411 . \mathrm{mol}^{-1} \cdot \mathrm{cm}^{-1}\right)$ and 260 $\mathrm{nm}$ (B-band, $\left.\varepsilon=11671 . \mathrm{mol}^{-1} \cdot \mathrm{cm}^{-1}\right)$, in contrast to the

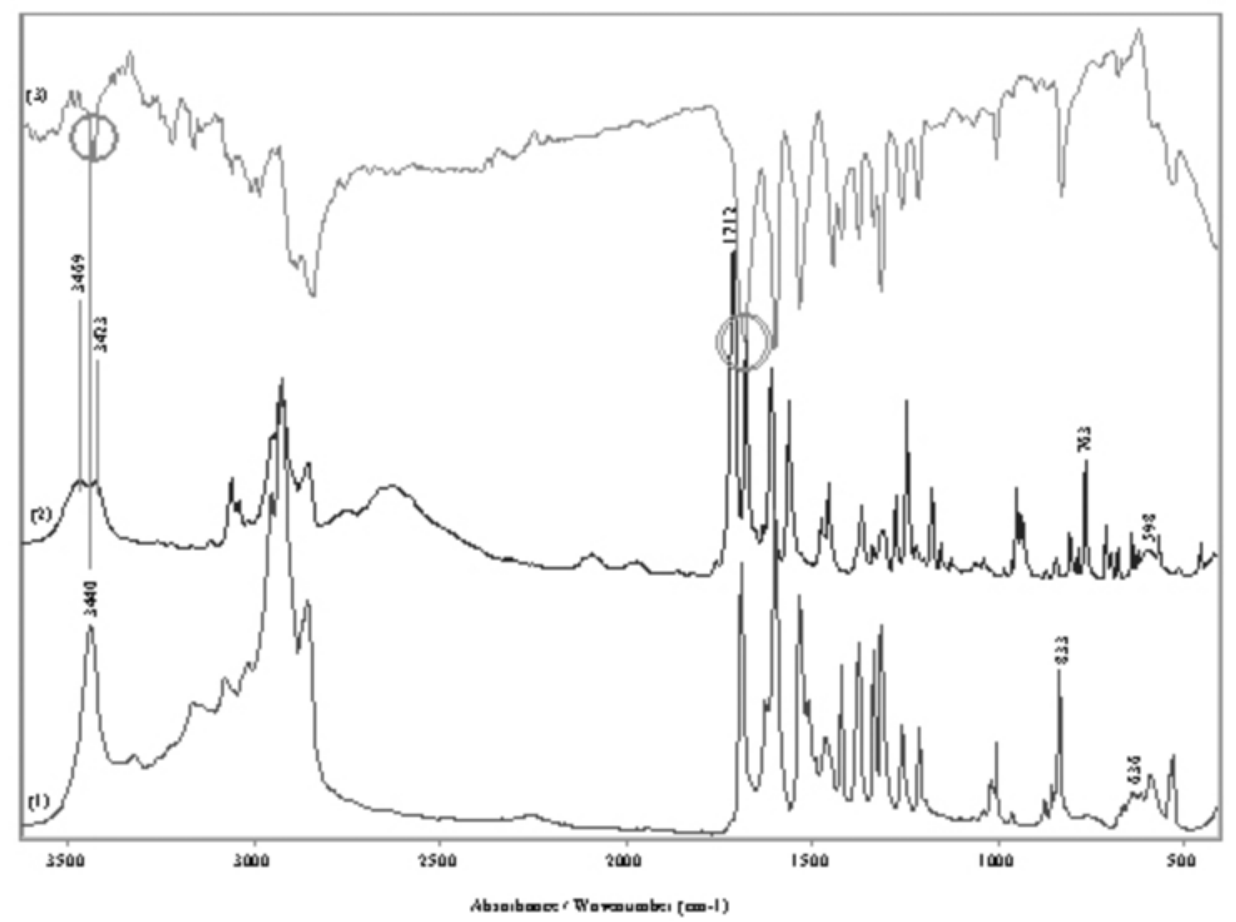

Figure 4. Non-polarized IR spectra of 4-acetaminopyridine dihydrate (1) and its protonated form (2) and reduced IR-LD spectrum of (1) after elimination of the band at $3440 \mathrm{~cm}^{-1}$ (3) 
mentioned pyridinium derivatives where only the first band is typical. The $\mathrm{N}_{\mathrm{py}}$ protonation leads only to a weak bathochromic effect for the first maximum $(4 \mathrm{~nm})$ as well as the hypochromic one $\left(\varepsilon 23511 . \mathrm{mol}^{-1} \cdot \mathrm{cm}^{-1}\right)$. These results give future support to an assumption about the retention of aromatic character in (1) following of $\mathrm{N}_{\mathrm{py}}$ protonation. Moreover, our theoretical calculations for (2) in aqueous solution give bands at $245 \mathrm{~nm}$ and $266 \mathrm{~nm}$ with $\mathrm{E}=4.72$ and $3.21 \mathrm{eV}$ and $\mathrm{f}=0.2934$ and 0.3421 , respectively

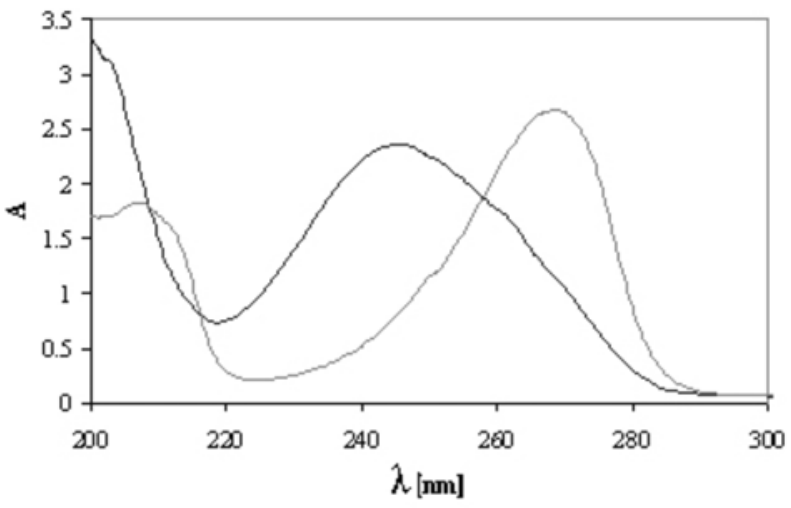

Figure 5. UV-spectra of neutral (black) and protonated form (grey) in solution

\section{${ }^{1} \mathrm{H}$ and ${ }^{13} \mathrm{C}$-NMR data in solution}

The ${ }^{1} \mathrm{H}-\mathrm{NMR}$ spectrum of (1) exhibits chemical shift differences $\Delta \delta$ for the signals of the aromatic protons in the range $7.83-7.96 \mathrm{ppm}$ of $0.04 \mathrm{ppm}(\mathrm{H} 2, \mathrm{H} 3), 0.05$ ppm (H5) and $0.13 \mathrm{ppm}$ (H6) in comparison to the corresponding data for (2), which unambiguously confirms the conclusion that $\mathrm{N}_{\mathrm{py}}$ protonation leads to the retention of the aromatic character. This protonation also has practically no affect on the ${ }^{13} \mathrm{C}-\mathrm{NMR}$ chemical signals and $\Delta \delta$ values of less then $0.1 \mathrm{ppm}$ are observed. These results are similar to those obtained for other pyridinium derivatives, where the aromatic and quinoid-like form have been characterized spectroscopically ${ }^{14-17}$.

\section{CONCLUSION}

We have reported on the spectroscopic and structural elucidation of 4-acetaminopyridine dihydrate and its protonated form, stabilized as the hydrochloride, by means of single crystal X-ray diffraction, linear-polarized solid state IR-spectroscopy (IR-LD), UV-spectroscopy, TGA, DSC, and positive and negative ESI MS. Quantum chemical calculations were used to obtain the electronic structure, vibrational data and electronic spectra. The first compound crystallizes in the centrosymmetric space group $\mathrm{P} 2_{1} / \mathrm{n}$ and contains two nonequivalent moleciules, connected by moderate intermolecular, $\mathrm{NH} . . . \mathrm{OH}_{2}(2.901$, $2.883 \AA), \mathrm{HOH} \ldots \mathrm{O}=\mathrm{C}(2.832,2.819 \AA)$ and $\mathrm{HOH} . . . \mathrm{N}_{\mathrm{py}}$ $(2.830,2.855 \AA)$, hydrogen bonds, leading to the formation of infinite layers. The amide fragment is transconfigurated with dihedral angle values of $177.3(6)^{\circ}$ and $179.7(8)^{\circ}$, respectively. The comparison of the optical and magnetic properties of (1) and (2) both in solution and in the solid state, shows that in contrast to the monoprotonated salts of 4-aminopyridine, 4dimethylaminopyridide or 3,4-diaminopyridine, where the quinoid-like form or partial aromatic distortion of pyridine have been observed ${ }^{14}-{ }^{17}$. The $\mathrm{N}_{\mathrm{py}}$ protonation of 4acetaminopyridine has practically no significant influence on the spectroscopic properties of the aromatic pyridine fragment.

\section{Acknowledgements}

B.K. wishes to thank the Alexander von Humboldt Foundation for a Fellowship and T.K. the DAAD for the grant within the priority program "Stability Pact SouthEastern Europe" and the Alexander von Humboldt Foundation

\section{Supporting information}

Crystallographic data for the structural analysis have been deposited with the Cambridge Crystallographic Data Centre, CCDC 697434 Copies of this information may be obtained from the Director, CCDC, 12 Union Road, Cambridge, CB2 1EZ, UK (Fax: +44 1223336 033; email: deposit@ccdc.cam.ac.uk or http:// www.ccdc.cam.ac.uk).

\section{LITERATURE CITED}

1. Molgo, J., Lemeignan, M., Peradejordi, F. \& Lechat, P. (1985). Presynaptic effects of aminopyridines on the neuromuscular junction of vertebrates J. Pharmacol. (Paris) 16, $109-121$.

2. Kirsch, G.E., Yeh, J.Z. \& Oxford, G.S. (1986). Modulation of aminopyridine block of potassium currents in squid axon, Biophys. J. 50, $637-644$.

3. Molgo, J., Lemeignan, M., Lechat, P. \& Peradejordi, F. (1985). Increase in evoked transmitter release from motor nerve terminals by some amino N-heterocyclic compounds I. Comparative experimental activities and extracellular $\mathrm{pH}$-dependence, Eur. J. Med. Chem. 20, 149 - 153.

4. Carlsson, C., Rosen, I. \& Nilsson, E. (1993) Can 4Aminopyridine be Used to Reverse Anaesthesia and Muscle Relaxation? Acta Anaesthesiol. Scand., 27, 87 - 90.

5. Schwid, S., Petrie, M., McDermott, M., Tierney, D., Maso, D. \& Goodman, A. (1997). Quantitative assessment of sustained-release 4-aminopyridine for symptomatic treatment of multiple sclerosis, Neurology 48, 817 - 821 .

6. McEvoy, K.M., Windebank, A.J., Daube, J.R. \& Low, P.A., (1989). 3,4-Diaminopyridine in the treatment of Lambert-Eaton myasthenic syndrome. New Engl. J. Med. 321, 1567 $-1571$.

7. Segal, J.L. \& Brunnemann, S.R. (1997). 4-Aminopyridine improves pulmonary function in quadriplegic humans with long-standing spinal cord injury. Pharmacotherapy 17, 415 423.

8. Sellin, L.C. (1981). The action of botulinum toxin at the neuromuscular junction. Med. Biol. 59, $11-20$.

9. Davidson, M., Zemishlany, J.H. \& Mohs, R.C. (1988). Alzheimer's Disease: A Report of Progress in Research. Biol. Psychiatry 23, 485 - 490.

10. Meves, H. \& Pichon, H. (1979). The effects of 4aminopyridine on the potassium current in internally profused giant axons of the squid. J. Physiol. Lond. 251, $60-63$.

11. Raust, J., Goulay-Dufay, S., Le Hoang, M., Pradeau, D. \& Guyon, F. (2007). Stability studies of ionised and nonionised 3,4-diaminopyridine: Hypothesis of degradation pathways and chemical structure of degradation products, $J$. Pharmaceut. Biomed. Anal. 43, 83 - 88.

12. Ivanova, B. \& Mayer-Figge, H. (2005). Crystal structure and Solid state IR-LD spectral analysis of new mononuclear $\mathrm{Cu}$ (II) complex with 4-aminopyridine. J. Coord. Chem. 58, 653 -659 . 
13. Ivanova, B., Arnaudov, M. \& Mayer-Figge, H. Molecular spectral analysis and crystal structure of 4-aminopyridinium tetrachloropalladate(II) complex salt. (2005). Polyhedron 24(13), $1624-1630$.

14. Koleva, B., Trendafilova, E., Arnaudov, M., Sheldrick, W.S. \& Mayer-Figge, H. (2006). Structural analysis of a mononuclear copper(II) complex of 3-aminopyridine. Trans. Met. Chem. 31, 866 - 873.

15. Koleva, B.B., Kolev, T., Tsanev, T., Kotov, St., MayerFigge, H., Seidel, R.W. \& Sheldrick, W.S. (2008). Spectroscopic and structural elucidation of 3,4-diaminopyridine and its hydrogentartarate salt. Crystal structure of 3,4diaminopyridinium hydrogentartarate dehydrate. J. Mol. Struct. $881,146-155$.

16. Koleva, B.B., Kolev, T., Tsanev, T., Kotov, St., MayerFigge, H., Seidel, R.S. \& Sheldrick, W.S. (2008). 3,4diaminopyridine bis(perchlorate): structural and spectroscopic elucidation? Struct. Chem. 19(1), 13 - 20.

17. Koleva, B.B., Kolev, T., Seidel, R.W., Tsanev, T., MayerFigge, H., Spiteller, M. \& Sheldrick, W.S. (2008). Spectroscopic and structural elucidation of 4-dimethylaminopyridine and its hydrogensquarate. Spectrochim. Acta, Part A, 71,. 695 - 702.

18. Emsley, J., Arif, M., Bates, P. \& Hursthouse, M. (1988). Bis(acetato)bis[4-(N-acetylamino)pyridine]aquacopper(II)-hydrogen fluoride-hydrate (1/2/2): X-ray structure reveals $\mathrm{H}_{2} \mathrm{O} \cdot \mathrm{HF}$ hydrogen bonded in the lattice. J. Chem. Soc. Dalton. Trans. 1493 - 1497.

19. Aakeroy, C.B., Hussain, I., Forbes, S. \& Desper, J. (2007). Exploring the hydrogen-bond preference of $\mathrm{N}-\mathrm{H}$ moieties in co-crystals assembled via $\mathrm{O}-\mathrm{H}($ acid) $\mathrm{N}(\mathrm{py})$ intermolecular interactions. Cryst. Eng. Comm. 9, 46 - 55.

20. Sheldrick, G.M. 1995, SHELXTL, Release 5.03 for Siemens R3 crystallographic research system. Siemens Analytical X-Ray Instruments, Inc., Madison, USA.

21. Sheldrick, G.M. 1997, SHELXS97 and SHELXL97. University of Göttingen,Germany.

22. Ivanova, B.B., Arnaudov, M.G. \& Bontchev, P.R. (2004). Linear-dichroic infrared spectral analysis of $\mathrm{Cu}(\mathrm{I})$-homocysteine complex. Spectrochim Acta 60(4)A, 855 - 862.

23. Ivanova, B.B.; Tsalev, D.L. \& Arnaudov, M.G. (2006). Validation of reducing-difference procedure for the interpretation of non-polarized infrared spectra of $n$-component solid mixtures. Talanta 69, $822-828$.

24. Ivanova, B.B., Simeonov, V.D., Arnaudov, M.G. \& Tsalev, D.L. (2007). Linear-dichroic infrared spectroscopy validation and experimental design of the orientation technique as suspension in nematic liquid crystal. Spectrochim Acta $67 \mathrm{~A}, 66-75$.

25. Koleva, B.B., Kolev, T., Simeonov, V., Spassov, T. \& Spiteller, M. (2008). Linear polarized IR-spectroscopy of partial oriented solids as a colloid suspension in nematic liquid crystal - new tool for structural elucidation of the chemical compounds. J. Incl. Phen, 61, 319 - 333.

26. Frisch, M.J., Trucks, G.W., Schlegel, HB., Scuseria, G.E., Robb, M.A., Cheeseman, J.R., Zakrzewski, V.G., Montgomery, Jr.J.A., Stratmann, R.E., Burant, J.C., Dapprich, S., Millam, J.M., Daniels, A.D., Kudin, K.N., Strain, M.C., Farkas, Ö., Tomasi, J., Barone, V., Cossi, M., Cammi, R., Mennucci, B., Pomelli, C., Adamo, C., Clifford, S., Ochterski, J., Petersson, G.A., Ayala, P.Y., Cui, Q., Morokuma, K., Salvador, P., Dannenberg, J.J., Malick, D.K., Rabuck, A.D., Raghavachari, K., Foresman, J.B., Cioslowski, J., Ortiz, J.V., Baboul, A.G., Stefanov, B.B., Liu, G., Liashenko, A., Piskorz, P., Komáromi, I., Gomperts, R., Martin, R.L., Fox, D.J., Keith, T., Al-Laham, M.A., Peng, C.Y., Nanayakkara, A., Challacombe, M., Gill, P.M.W., Johnson, B., Chen, W., Wong, M.W., Andres, J.L., Gonzalez, C., Head-Gordon, M., Replogle, E.S. \& Pople, J.A. Gaussian 98, Gaussian, Inc., Pittsburgh, PA, 1998.

27. Zhurko, G.A. \& Zhurko, D.A., ChemCraft: Tool for treatment of chemical data, Lite version build 082005 . 